\title{
Epithelial-Mesenchymal Transition-Inducing Factors Involved in the Progression of Lung Cancers
}

\author{
Min-Woo Nam, Cho-Won Kim and Kyung-Chul Choi* \\ Laboratory of Biochemistry and Immunology, College of Veterinary Medicine, Chungbuk National University, Cheongju 28644, \\ Republic of Korea
}

\begin{abstract}
Although there have been advances in cancer therapy and surgical improvement, lung cancer has the lowest survival rate (19\%) at all stages. This is because most patients are diagnosed with concurrent metastasis, which occurs due to numerous related reasons. Especially, lung cancer is one of the most common and malignant cancers in the world. Although there are advanced therapeutic strategies, lung cancer remains one of the main causes of cancer death. Recent work has proposed that epithelialmesenchymal transition (EMT) is the main cause of metastasis in most cases of human cancers including lung cancer. EMT involves the conversion of epithelial cells, wherein the cells lose their epithelial abilities and become mesenchymal cells involved in embryonic development, such as gastrulation and neural crest formation. In addition, recent research has indicated that EMT contributes to altering the cancer cells into cancer stem cells (CSCs). Although EMT is important in the developmental stages, this process also activates lung cancer progression, including complicated and diverse signaling pathways. Despite the numerous investigations on signaling pathways involved in the progression of lung cancer, this malignancy is considered critical for treatment. EMT in lung cancer involves many transcription factors and inducers, for example, Snail, TWIST, and ZEB are the master regulators of EMT. EMT-related factors and signaling pathways are involved in the progression of lung cancer, proposing new approaches to lung cancer therapy. In the current review, we highlight the signaling pathways implicated in lung cancer and elucidate the correlation of these pathways, indicating new insights to treat lung cancer and other malignancies.
\end{abstract}

Key Words: EMT, Lung cancer, Metastasis, FOXC2, E-cadherin, N-cadherin, Snail

\section{INTRODUCTION}

Despite the advances in cancer diagnosis and surgical development, the survival rate of lung cancer patients is $19 \%$ for all stages combined, with a large proportion of patients $(57 \%)$ diagnosed with metastasis and having a $5 \%$ survival rate in 2020 (Sung et al., 2021). Chemotherapy and drug administration are still the major strategies of treatment. However, some patients show resistance to chemotherapy or drugs, and metastasis is one of the leading causes of failure in cancer treatment (Wu and Wang, 2015). Epithelial-mesenchymal transition (EMT) is a conversion of epithelial cells to mesenchymal cells, where cells lose their epithelial properties and acquire invasiveness and migratory abilities (Hay, 2005). EMT is proposed to be one of the main causes of embryonic development, neural crest formation, and gastrulation (Thiery et al., 2009). EMT naturally occurs in many tissue types showing phenotypical changes. This transition makes epithelial cells exhibit increased motility and spindle-like morphology (Zhang and Weinberg, 2018). The key mechanism of EMT is the dissociation of the epithelial cells to cell junctions which leads to loss of pical-basal polarity and degrade extracellular matrix (ECM) to make them invade (Lamouille et al., 2014). However, EMT is more strikingly involved in tumor progression, with the presence of EMT being reported in numerous metastatic cancers (Lee et al., 2006b; Hugo et al., 2007). During EMT, epithelial cells lose the properties of cell-cell adhesion and cell polarity, with altered gene expressions. For example, one of the epithelial markers Epithelial-cadherin (E-cadherin) is decreased, whereas Neural-cadherin ( $\mathrm{N}$-cadherin), vimentin, and fibronectin are overexpressed (Thiery and Sleeman, 2006). Likewise, many transcription factors are involved in EMT. There are master regulators, for instance, Snail, TWIST, and ZEB are activated early in EMT. These transcription fac-

\section{Open Access https://doi.org/10.4062/biomolther.2021.178}

This is an Open Access article distributed under the terms of the Creative Commons Attribution Non-Commercial License (http://creativecommons.org/licenses/by-nc/4.0/) which permits unrestricted non-commercial use, distribution, and reproduction in any medium, provided the original work is properly cited.
Received Nov 26, 2021 Revised Jan 5, 2022 Accepted Jan 5, 2022

Published Online Jan 18, 2022

\section{*Corresponding Author}

E-mail:kchoi@cbu.ac.kr

Tel: +82-43-261-3664, Fax: +82-43-267-3150 
tors also often correlate the expression of each other target genes to induce EMT (Peinado et al., 2007). Over the past decades, numerous studies in lung cancer have investigated the signaling pathways and factors involved in EMT. Since these features are complicatedly connected, an easy systematization is required to provide an insight into the association between EMT and lung cancer (Barbera et al., 2004; Hodge et al., 2005; Zhou et al., 2016; Pires et al., 2017). However, it remains unclear how such signaling pathways influence other pathways to induce EMT. These other pathways also need to be organized and combined with new findings related to EMT. In the current review, we highlight the correlation between factors and signaling pathways involved in EMT (especially in lung cancer cells), and organize the recent findings in EMT and lung cancer. The importance of organizing the pathways with inducing factors is related to future studies focused on investigating the extent to these factors or pathways contribute to EMT in lung cancer. Therefore, it is imperative to have a thorough knowledge of what factors and pathways are included in the process.

\section{DEVELOPMENTAL PROGRESS WITH EMT}

\section{EMT and gastrulation}

Gastrulation comprises the formation of the gut, which includes EMT. When epithelial cells convert into mesenchymal cells, the cells obtain an irregular morphology and lose the features of epithelial cells (Hugo et al., 2007). EMT is a process of development, such as egg cleavage or cellularization (Fazilaty et al., 2019). It is also involved in blastula formation, where cells undergo reorganization to establish the three primary germ layers, viz., ectoderm, mesoderm, and endoderm (Acloque et al., 2009). Before EMT, the epithelial cells acquire plasticity (Chin and Lim, 2019), and are subsequently able to remodel through various processes such as cell intercalation, invagination, evagination, branching, and multi-layering. Cells can also reversibly or irreversibly alter into mesenchymal cells through EMT (Thiery and Sleeman, 2006). For example, when cellularization ends in drosophila, the mesoderm precursor cells start to invaginate, which seems like a topological rearrangement of an intact epithelium. Mesoderm cells show a mesenchymal morphology after the invaginated mesoderm precursors obtain some epithelial characteristics. This important process often allows the formation of the three-layered embryo during gastrulation (Leptin, 1999; Leptin and Affolter, 2004). The EMT commences with a convergence of secreted signals like Wingless-related integration site (Wnt), nodal, fibroblast growth factor (FGF), bone morphogenetic protein (BMP), and some transcription factor expressions. The basement membrane collapses when the EMT works on during gastrulation after apical constriction (Arnold and Robertson, 2009). Also, research involving mouse Crumbs2 (CRB2) revealed that cell ingression is induced during gastrulation. Studies have validated the role of CRB2 during gastrulation in directing stochastic actomyosin-dependent cell ingression (Tepass et al., 1990; Tepass, 1996). Thus, it has been determined that during gastrulation, EMT plays a key role to form a three-layered embryo, and gastrulation is the first step in embryonic development.

\section{EMT and neural crest formation}

The first step of EMT occurs during early embryonic development. After the formation of the mesoderm through gastrulation, neural crest (NC) formation is the primary process in EMT, which has an ability to differentiate into various cell types (Buckingham et al., 2003). Formation of the NC during EMT takes place in the early embryo, and its precursors undergo EMT to migrate to distant parts and differentiate into various derivatives such as schwannomas and gliomas (Boutet et al., 2007; Acloque et al., 2009; Thiery et al., 2009). For example, $\mathrm{NC}$ is evidently the source of mesectodermal derivatives in the vertebrate head and neurons, glia, pigment cells of the skin, and chromaffin (Weston, 1970; Basch et al., 2006; Bronner, 2012). The NC is induced by a few signaling factors, and the induction of NC is initiated with a combination of BMP, Wnt, and FGF signaling, which set up the neural plate border territory during the gastrula stage (Monsoro-Burq et al., 2005; Ezin et al., 2009). Wnt is one of the main factors in NC formation. The canonical Wnt signaling pathway induces and stabilizes the NC cell precursors, and the subsequent expression of BMP activates the EMT via inducing c-Myb, which activates Snail2 (Karafiat et al., 2005, 2007). A group of essential transcription factors (neural plate border specifier genes) regulated by extracellular signals is believed to turn on the EMT program in the dorsal neural tube (Sauka-Spengler and Bronner-Fraser, 2008). A complicated series of cellular events which control regulators in the NC, permit the NC cells to emigrate from the neural tube. Another example of EMT is the generation of the NC during embryogenesis. Neural crest migrating over a long distance is ruled out from the neural epithelium, and development is at the boundary between the neural plate and the epidermal ectoderm. During this process, the NC loses $\mathrm{N}$-cadherin-mediated cell-cell adhesion (Tucker et al., 1988; Duband et al., 1995; Bronner-Fraser, 2002). Hence, a harmony of transcription factors and signaling pathways involved in EMT is required for the formation of NC cells after gastrulation. Among the various processes during embryonic development, gastrulation and the formation of NC are associated with EMT.

\section{EMT and fibrosis}

EMT is also involved in fibrosis, and the role of EMT leading to organ fibrosis in tissue injury is now getting defined. Sufficient evidence indicates that EMT is related to progressive kidney disease (Kalluri and Neilson, 2003), and probably in the lung (Chilosi et al., 2003) and liver afflictions. For example, the fibrosis of bleomycin-induced lung was induced by the Wnt1 signaling pathway which initiates EMT (Otsuki et al., 2018). Progressive fibrotic diseases of the lung involve EMT. Eric Neilson has investigated fibroblast specific protein 1 (FSP1), which is a marker for EMT (Okada et al., 1996). The expression of FSP1 can disaggregate organ tissues which leads to avoiding differentiating during fibrogenesis (Iwano et al., 2002; Kalluri and Neilson, 2003). FSP1 contributes to fibrosis, and upregulation of FSP1 correlates with the prognosis and extent of fibrosis (Nishitani et al., 2005). The reduction of FSP1 cells weakens the fibrosis and collagen deposition, which is a causal role for these cells in fibrotic diseases (Iwano et al., 2001). Kidney FSP1-positive cells originate from the bone marrow, and EMT has been detected at sites of renal fibrosis (Iwano et al., 2002). In renal tubular epithelial cells, the transforming growth factor- $\beta$ (TGF- $\beta$ ) induces EMT and expression of FSP1 (Fan et al., 1999; Strutz et al., 2002). The upregulation 
of TGF- $\beta$ is induced by (TBM) disintegration (Zeisberg et al., 2001). One in vitro study has also reported that E-cadherin, in a SMAD-dependent manner, leads to an event wherein the tubular epithelial cells can be reversed by BMP7 in TGF- $\beta$ induced EMT (Kalluri and Neilson, 2003). BMP7 is one of the BMP family of TGF- $\beta$ growth factors, and acts as a morphogen in liver development. Kalluri and Neilson (2003) reported that EMT may play an important role in TGF- $\beta 1$-mediated cardiac fibrosis. Kalluri and Neilson (2003) also demonstrated that cardiac fibrosis can be inhibited by an inhibitor of TGF- $\beta$ signaling, viz., BMP7. BMP7 is an endogenous antagonist of TGF- $\beta$-induced EMT and it increases the expression of Ecadherin induced by TGF- $\beta$ (Kalluri and Neilson, 2003; Lee et al., 2006a). Also, several studies have demonstrated that EMT is related to the expression of FSP1 during renal fibrosis (Strutz et al., 1995; Okada et al., 1997). The presence of FSP1 has been determined in tubular epithelial cells undergoing a transition in damaged nephrons (Okada et al., 1997, 2000). Increasing numbers of unhealthy fibroblasts were shown to be accumulated in the intermediate layer of the kidney through the damaged tubular basement membrane (TBM) (Okada et al., 1996). These FSP1 epithelia eventually lose their epithelial markers, indicating that EMT contributes to fibrosis, which is increasing rapidly.

\section{EMT AND CANCER PROGRESSION}

In lung cancer, evidence supports a critical role for EMT in cancer progression and metastasis. For example, TGF- $\beta$ induces EMT in lung cancer cells, and subsequently activates SMAD, phosphatidylinositol 3-kinase (PI3K)-AKT, and Rasmitogen-activated protein kinase (MAPK) pathways (Shaw and Solomon, 2011). Those transcription factors have been investigated and determined to result in the development of lung cancer, including metastasis (Shih et al., 2005; Wang et al., 2011). Conversion of lung cancer cells into mesenchymal cells acquiring mesenchymal properties activates proteolysis and motility, resulting in metastasis of tumor cells and formation of a secondary tumor at distant sites. Numerous genes regulate EMT in lung cancer, such as the Snail family transcriptional repressor (SNAI1). SNAI1 regulates the expression of numerous genes related to EMT in colorectal cancer cells (De Craene et al., 2005) indicating that EMT is regulated by several signaling pathways which are connected complicatedly (Seo et al., 2021). Additionally, many EMT-inducing transcription factors such as Snail, Slug, $\delta E F 1$, SMAD interacting protein 1 (SIP1), twist family bHLH (basic helix-loop-helix) transcription factor 1 (TWIST1), and forkhead box protein C2 (FOXC2) have been correlated with lung cancer progression, and expression of these genes has also been determined in certain invasive human and mouse tumor cell lines.

Upregulated genes related to EMT are associated with poorly differentiated tumors in breast cancer (Teschendorff et al., 2007). The loss of E-cadherin and expression of $\mathrm{N}$-cadherin are examples indicative of prostate cancer progression (Gravdal et al., 2007). However, considering lung cancer and its progression with EMT remains complicated. For example, despite the overexpression of EMT-associated genes in lung cancer, neither $\mathrm{E}$-cadherin nor $\mathrm{N}$-cadherin is related to nonsmall lung cancer cells (Prudkin et al., 2009). Further investigations are required to define the association of each signaling pathway, and to characterize the role of EMT in lung cancer.

\section{EMT AND INDUCING FACTORS IN LUNG CANCER}

\section{TWIST, Goosecoid, and FOXC2}

One research team reported that TWIST, Goosecoid, and FOXC2 are transcription factors that regulate developmental EMT and have a critical role in metastasis. These genes are highly expressed, and the gene products facilitate metastasis in mouse models and human tumors. The TWIST is a basic helix-loop-helix transcription factor that was identified as an EMT activator (Castanon and Baylies, 2002). In recent findings of TWIST, the recent study found that long noncoding RNAs in TWIST1 were heightened in lung cancer metastatic tissues. This was caused by activating the $\mathrm{Wnt} / \beta$-catenin signaling pathway (Pan et al., 2020). The research team showed that the expression of TWIST induces an in vitro EMT in breast cells. When TWIST is inactivated, the development of metastasis is inhibited in vivo (Yang et al., 2004). Goosecoid is a homeobox transcriptional inhibitor that controls the Spemann organizer in vertebrate gastrulation, and is one of the first identified embryonic pattern modulators (De Robertis et al., 2001). Both TWIST and Goosecoid regulate FOXC2, one of the FOX family of forkhead helix-turn-helix DNA-binding proteins, which manipulates EMT and development in many tissues (Carlsson and Mahlapuu, 2002). TWIST, Goosecoid, and Snail 1 suppress E-cadherin, induce FOXC2, and improve cell migration. However, there has been no investigation clarifying whether pathways of these three genes are correlated. Importantly, the upregulation of mesenchymal gene transcription is directly induced by FOXC2.

All the above genes are expressed in certain invasive mouse and human cancer cell lines, and especially TWIST1 is reported to be crucial for metastasizing in mouse breast cancer cells, from the mammary to the lung (Yang et al., 2004). The human carcinoma cells also gain the ability to disseminate with overexpression of FOXC2 or Goosecoid (Hartwell et al., 2006; Mani et al., 2007). Induction of EMT signal involves TGF- $\beta$ signaling in multiple human cancer cell lines. When the tumor enters the later stage, the cells begin to activate EMT and spread to other organs. TGF- $\beta$ induces Snail, slug, and SIP1, and also induces a loss of cell-cell adhesion by suppressing the expression of E-cadherin (Lander et al., 2011).

\section{GSK3 $\beta$, PAK1, and SNAI1}

Another example of an EMT regulator in lung cancer is glycogen synthase kinase $3 \beta$ (GSK3 $\beta$ ). GSK3 $\beta$ is inhibited by the protein kinase $B(A K T / P K B), W n t$, and Hedgehog pathways (Polakis, 2000; Grille et al., 2003). GSK3 $\beta$ phosphorylates several transcription factors including Snail, p53, Myc, and nuclear factor of activated T cells (NFAT), which induce its nuclear export (Beals et al., 1997; Zhou et al., 2004). GSK3 $\beta$ phosphorylates two Ser residues on Snail, one of which induces SNAI1 for ubiquitination and degradation, whereas the other induces its nuclear export. The inhibition of GSK3 $\beta$ leads to increased cellular levels of SNAl1 with downregulation of E-cadherin. SNAI1 also receives a signal from the epidermal growth factor (EGF) through p21-activated kinase-1 (PAK1) (Yang et al., 2005). PAK1 induces phosphorylation of SNAI1 on a different Ser residue of GSK3 $\beta$, resulting in accumulation of SNAI1 in the nucleus and subsequent SNAI1-mediated 


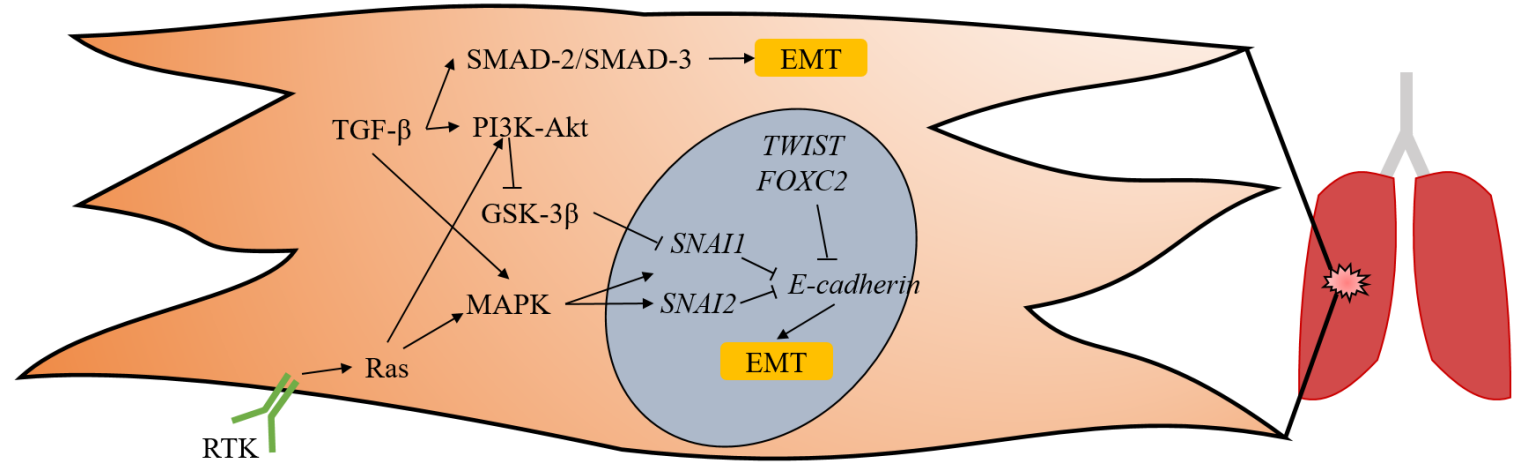

Fig. 1. Overview of the signaling pathways during EMT in lung cancer. Several signaling pathways which induce epithelial-mesenchymal transition (EMT) are selected. Transforming growth factor- $\beta$ (TGF- $\beta$ ) plays a key role in lung cancer cells during EMT, activating mitogen activated protein kinase (MAPK), SMAD2, and SMAD3 to induce EMT. It also induces the phosphoinositide 3-kinase-protein kinase B (PI3KAkt) pathway which subsequently suppresses the glycogen synthase kinase-3 $\beta$ (GSK-3 $\beta$ ). GSK-3 $\beta$ then represses the expression of the snail family transcriptional repressor 1 (SNAI1). Conversely, the expression of SNAI1 and SNAI2 is activated by MAPK. This derives EMT by suppressing the expression of epithelial-cadherin (E-cadherin). E-cadherin is also downregulated by the twist family bHLH transcription factor (TWIST) and forkhead box protein C2 (FOXC2). Ras is activated by tyrosine kinase, which subsequently induces PI3K-AKT and MAPK, and eventually leading to EMT.

transcriptional repression of target genes. When the phosphorylation site of SNAI1 is mutated or the expression of PAK1 is downregulated, the SNAI1 is accumulated in the cytoplasm and its transcriptional-repressor activity is reduced. Taken together, these results indicate how several different signaling pathways communicate to manipulate EMT under the influence of SNAI1 and its activity (Thiery and Sleeman, 2006).

\section{TGF- $\beta$}

A number of signal factors involved in EMT have been identified, including FGF, Wnt, and Notch proteins. Several studies revealed that some signaling pathways involved in EMT are able to communicate with each other (Timmerman et al., 2004). TGF- $\beta$ is one of the most studied inducers of EMT. The recent study investigated the effect of TGF- $\beta$ on the expression levels of EMT through next-generation sequencing. They found that TGF- $\beta$ causes the demethylation of H3K27me3 in the Snail1 promoter and increases the expression of Snail1 leading to EMT (Kim et al., 2020). Another example, TGF- $\beta 2$ and TGF- $\beta 3$ control the atrioventricular canal and palate-fusion EMT, respectively (Wang et al., 2005). When the TGF- $\beta$ binds to its receptors, Smad2 and Smad3 are activated through $\mathrm{C}$-terminal phosphorylation. Activated Smad2 and Smad3 then bind to Smad4 to form trimers, and this complex subsequently migrates into the nucleus where it interacts with the DNA binding transcriptional factors. This results in regulating the expressions of TGF- $\beta$ target genes (Fuxe et al., 2010). To get high affinity and selectivity for the target gene, SMAD transcriptional factors must correlate with cofactors like Snail and zinc finger E-box binding homeobox (ZEB) factors because of their low affinity to DNA. In TGF- $\beta$ induced EMT, Smad3, Smad4, and TGF- $\beta$ receptors are critical factors (Valcourt et al., 2005). TGF- $\beta$ is also involved in other signaling pathways such as Wnt (Eger et al., 2004; Shin et al., 2010), Notch (Timmerman et al., 2004), and Ras-MAPK (Xie et al., 2004), leading to EMT.

Furthermore, receptor-mediated signaling in response to these ligands activates intracellular effector molecules. For example, the small GTPase family (Ras, Rho, and Rac) are members of the Src tyrosine kinase family. These factors are involved in altering the organization of the cytoskeleton and disassembling junctional complexes during EMT (Ungefroren et al., 2018). The induced signaling pathways lead to activation of transcriptional regulators such as snail (SNAI1) and slug (SNAI2), which are involved in managing the geneexpression patterns. The main role of SNAI1 in EMT has been studied, and it has been determined that the stability, subcellular localization, and function via different phosphorylation events are controlled by complicated regulations as seen in Fig. 1 (Barrallo-Gimeno and Nieto, 2005; Lim et al., 2013).

\section{Other EMT-inducing factors}

In certain carcinoma cells, overexpression of E-cadherin represses the invasive and metastatic ability; conversely, suppressing the E-cadherin function in noninvasive tumor cells induces invasion and metastasis (Frixen et al., 1991; Perl et al., 1998). The expression of E-cadherin ceases at the early stage of tumor development, resulting in tumors reflecting a mesenchymal phenotype. The formation of the E-cadherinmediated adherent junction is downregulated by several tyrosine kinases in cancer cells (Guilford et al., 1998). Additionally, E-cadherin is also phosphorylated and binds to Hakai E3-ligase. The phosphorylated E-cadherin-Hakai complexes are then internalized to endosomes and degraded in lysosomes. Thus, cell adhesion in tumor cells is disrupted by activating tyrosine kinase (Fujita et al., 2002; Pece and Gutkind, 2002). Additionally, subsequent to the loss of cell-cell adhesion, the cells must modulate the integrin-mediated contacts with the extracellular matrix (ECM). Recent work has shown an extensive correlation between integrin signaling and pathways that control EMT. For example, MAPK-p38 induces TGF- $\beta$ signaling and relies on signaling by $\beta 1$ integrin. Conversely, the expression of disabled-2 (DAB2) induced by TGF- $\beta$ binds to $\beta 1$ integrin, leading to integrin activation and the formation of focal adhesions (Bhowmick et al., 2001). Several research teams have reported that the downregulation of E-cadherin promotes integrins, as endocytosis of E-cadherin activates the small GTPase Rap1 which is a protein that modulates 
integrins to activate, and is needed to form focal adhesions (Balzac et al., 2005). Interestingly, integrins can downregulate E-cadherin in various ways; e.g., integrin-linked kinase (ILK) interacts with the cytoplasmic domain of $\beta 1$ and $\beta 3$ integrins so that ILK can suppress the expression of E-cadherin ( $\mathrm{Li}$ et al., 2003; Oloumi et al., 2004).

\section{EMT AND CANCER STEM CELLS}

Recent evidence suggests that EMT is involved in acquiring cancer stem cell (CSC) features, such as the capacity for self-renewal (Sato et al., 2016). CSCs account for a minimal portion of tumor cells, and can differentiate into heterogeneous lineages of cancer cells. Cells that originate in EMT have cancer stem cell-like features. Subsequent to the cancer cells undergoing metastasis in lung cancer, the secondary tumor requires the abilities of CSCs. However, the correlation between EMT and CSC remains unclear. Studies reveal that several transcription factors are involved in CSCs (Maiuthed et al., 2018). One research team identified that mammary epithelial cells initiate EMT by upregulating Snail, Twist, or TGF- $\beta$. Further investigations revealed that the mesenchymal cells induced by EMT are able to differentiate into osteoblast, adipocytes, and chondrocytes. The study also ascertained a correlation between cancer stem cells and EMT (Hao et al., 2014).

Conversely, studies have reported the transcriptional regulation of EMT. For example, the transcriptional repressor ZEB1 and miR-200 family of miRNAs are reported to modulate EMT by intervening in a negative feedback loop (Bracken et al., 2008). ZEB1 suppresses the expressions of miR-200 and miR-203 which inhibits stemness. These features suggest the interaction between cancer stem cells and EMT (Zhang et al., 2015). Besides, miR-200, miR-203, and miR-183 contribute to the downregulation of stem cell factors in tumor cells (Wellner et al., 2009), and especially, the candidate factors of miR200 are known to participate in stem cells such as Sox2 and KIf4 (Wang et al., 2013). Recent work has shown that AT2, cell-specific marker surfactant apoprotein-C (SP-C), and CCA (Clara cell-specific marker) are found in normal lung and lung cancer cells (Kim et al., 2005). Since ZEB1 regulates cancer cells at the transcriptional level, it is also involved in cell motility, which is one of the main characteristics of cancer cells. In the early phase of tumorigenesis, ZEB1 activates the Kirsten rat sarcoma virus (KRAS) mutation in the PI3K-Akt signaling pathway by suppressing the expression of the phosphatase and tensin homolog (PTEN) (Liu et al., 2014). Given that there have been more advances in studies of ZEB1, regulation of ZEB1 might be useful to treat lung cancer. However, further studies are required to identify the correlation between lung cancer stem cells and EMT.

\section{CONCLUSION}

The conversion of epithelial cells to mesenchymal cells is a crucial step for cell heterogeneity when considering the potential fates during embryonic development. Numerous genes are involved during the development stage. We first focused on what factors are related to EMT during the process of gastrulation, which leads to the formation of the three germ lay- ers capable of differentiating into all tissue types. This process includes several transcription factors including Wnt, FGF, and BMP. EMT is initiated after gastrulation, leading to the subsequent formation of the NC. NC loses the property of cell-cell adhesion, and converts into mesectodermal derivatives in the vertebrate. The EMT is involved not only during development, but also in fibrosis. FSP1 plays a key role in fibrosis. During fibrosis, EMT is associated with the expression of FSP1. As presented above in the previous sections, several studies have proposed that fibrotic diseases of the lung include EMT.

EMT is also associated with tumorigenesis and metastasis. Excessive proliferation of epithelial cells can be the origin of a primary tumor. When this tumor attains the ability to change into mesenchymal cells which can migrate to other organs, the tumor cells undergo EMT. In the case of lung cancer progression, the cancer cells convert into mesenchymal cells to activate proteolysis and motility. Consequently, the cancer cells metastasize and establish a secondary tumor at distant sites. SNAI1 is one of the EMT-inducing factors which regulate the expression of genes related to EMT. However, various complicated signaling pathways are involved in EMT; hence, we have accumulated the characteristics and pathways of EMT to rearrange and introduce their correlation. It is well recognized that cancer cells undergo EMT which leads to metastasis, and this can be associated with cancer stem cells. Despite discovery of the many pathways of EMT, the extent of participation of the inducing factors and the pathways in lung cancer cells with EMT remains unclear. The contribution of each pathway during EMT needs to be investigated to understand the level of contribution. In addition, we propose that manipulating the efficacy of EMT-inducing factors can be a new approach in lung cancer treatment. Increasing studies are now indicating that targeting EMT-related signaling pathways is a new approach to treat lung cancer and other malignancies. Our review was undertaken to suggest insights into how we might increase the efficacy of cancer therapy. In recent cancer treatments, the therapies are targeting not just one factor or signaling pathway, but rather multiple targets. Thus, understanding how factors and signaling pathways are associated with EMT is important to treat cancer effectively, and this review might give an insight in conjunction with other EMT-targeted treatments. Future studies need to uncover the correlation between EMT and lung cancer, with unidentified or identified factors. Since one pathway or inducing factor might be influenced by another factor during EMT, researchers need to study not only factors that participate in EMT, but also the degree of their contributions.

\section{CONFLICT OF INTEREST}

The authors do not have any conflicts of interest to declare.

\section{ACKNOWLEDGMENTS}

This work was supported by the Basic Science Research Program (2020R1A2C2006060) and the Global Research and Development Center (GRDC) Program (2017K1A4A3014959) through the National Research Foundation (NRF) of Korea, funded by the Ministry of Science and ICT. This study was also supported by Regional Innovation Strategy (RIS; 
\#1345329680) through the National Research Foundation of Korea (NRF) funded by the Ministry of Education (MOE).

\section{REFERENCES}

Acloque, H., Adams, M. S., Fishwick, K., Bronner-Fraser, M. and Nieto, M. A. (2009) Epithelial-mesenchymal transitions: the importance of changing cell state in development and disease. J. Clin. Invest. 119, 1438-1449.

Arnold, S. J. and Robertson, E. J. (2009) Making a commitment: cell lineage allocation and axis patterning in the early mouse embryo. Nat. Rev. Mol. Cell Biol. 10, 91-103.

Balzac, F., Avolio, M., Degani, S., Kaverina, I., Torti, M., Silengo, L., Small, J. V. and Retta, S. F. (2005) E-cadherin endocytosis regulates the activity of Rap1: a traffic light GTPase at the crossroads between cadherin and integrin function. J. Cell Sci. 118, 47654783.

Barbera, M. J., Puig, I., Dominguez, D., Julien-Grille, S., Guaita-Esteruelas, S., Peiro, S., Baulida, J., Franci, C., Dedhar, S., Larue, L. and Garcia de Herreros, A. (2004) Regulation of Snail transcription during epithelial to mesenchymal transition of tumor cells. Oncogene 23, 7345-7354.

Barrallo-Gimeno, A. and Nieto, M. A. (2005) The Snail genes as inducers of cell movement and survival: implications in development and cancer. Development 132, 3151-3161.

Basch, M. L., Bronner-Fraser, M. and Garcia-Castro, M. I. (2006) Specification of the neural crest occurs during gastrulation and requires Pax7. Nature 441, 218-222.

Beals, C. R., Sheridan, C. M., Turck, C. W., Gardner, P. and Crabtree, G. R. (1997) Nuclear export of NF-ATc enhanced by glycogen synthase kinase-3. Science 275, 1930-1934.

Bhowmick, N. A., Zent, R., Ghiassi, M., McDonnell, M. and Moses, H. L. (2001) Integrin beta 1 signaling is necessary for transforming growth factor-beta activation of p38MAPK and epithelial plasticity. J. Biol. Chem. 276, 46707-46713.

Boutet, A., Esteban, M. A., Maxwell, P. H. and Nieto, M. A. (2007) Reactivation of Snail genes in renal fibrosis and carcinomas: a process of reversed embryogenesis? Cell Cycle 6, 638-642.

Bracken, C. P., Gregory, P. A., Kolesnikoff, N., Bert, A. G., Wang, J., Shannon, M. F. and Goodall, G. J. (2008) A double-negative feedback loop between ZEB1-SIP1 and the microRNA-200 family regulates epithelial-mesenchymal transition. Cancer Res. 68, 7846-7854.

Bronner-Fraser, M. (2002) Molecular analysis of neural crest formation. J. Physiol. Paris 96, 3-8.

Bronner, M. E. (2012) Formation and migration of neural crest cells in the vertebrate embryo. Histochem. Cell Biol. 138, 179-186.

Buckingham, M., Bajard, L., Chang, T., Daubas, P., Hadchouel, J., Meilhac, S., Montarras, D., Rocancourt, D. and Relaix, F. (2003) The formation of skeletal muscle: from somite to limb. J. Anat. 202 , 59-68.

Carlsson, P. and Mahlapuu, M. (2002) Forkhead transcription factors: key players in development and metabolism. Dev. Biol. 250, 1-23.

Castanon, I. and Baylies, M. K. (2002) A twist in fate: evolutionary comparison of Twist structure and function. Gene 287, 11-22.

Chilosi, M., Poletti, V., Zamo, A., Lestani, M., Montagna, L., Piccoli, P., Pedron, S., Bertaso, M., Scarpa, A., Murer, B., Cancellieri, A., Maestro, R., Semenzato, G. and Doglioni, C. (2003) Aberrant Wnt/betacatenin pathway activation in idiopathic pulmonary fibrosis. Am. J. Pathol. 162, 1495-1502.

Chin, V. L. and Lim, C. L. (2019) Epithelial-mesenchymal plasticityengaging stemness in an interplay of phenotypes. Stem Cell Investig. 6, 25.

De Craene, B., Gilbert, B., Stove, C., Bruyneel, E., van Roy, F. and Berx, G. (2005) The transcription factor snail induces tumor cell invasion through modulation of the epithelial cell differentiation program. Cancer Res. 65, 6237-6244.

De Robertis, E. M., Wessely, O., Oelgeschlager, M., Brizuela, B., Pera, E., Larrain, J., Abreu, J. and Bachiller, D. (2001) Molecular mechanisms of cell-cell signaling by the Spemann-Mangold orga- nizer. Int. J. Dev. Biol. 45, 189-197.

Duband, J. L., Monier, F., Delannet, M. and Newgreen, D. (1995) Epithelium-mesenchyme transition during neural crest development. Acta Anat. (Basel) 154, 63-78.

Eger, A., Stockinger, A., Park, J., Langkopf, E., Mikula, M., Gotzmann, J., Mikulits, W., Beug, H. and Foisner, R. (2004) beta-Catenin and TGFbeta signalling cooperate to maintain a mesenchymal phenotype after FosER-induced epithelial to mesenchymal transition. Oncogene 23, 2672-2680.

Ezin, A. M., Fraser, S. E. and Bronner-Fraser, M. (2009) Fate map and morphogenesis of presumptive neural crest and dorsal neural tube. Dev. Biol. 330, 221-236.

Fan, J. M., Ng, Y. Y., Hill, P. A., Nikolic-Paterson, D. J., Mu, W., Atkins, R. C. and Lan, H. Y. (1999) Transforming growth factor-beta regulates tubular epithelial-myofibroblast transdifferentiation in vitro. Kidney Int. 56, 1455-1467.

Fazilaty, H., Rago, L., Kass Youssef, K., Ocana, O. H., Garcia-Asencio, F., Arcas, A., Galceran, J. and Nieto, M. A. (2019) A gene regulatory network to control EMT programs in development and disease. Nat. Commun. 10, 5115

Frixen, U. H., Behrens, J., Sachs, M., Eberle, G., Voss, B., Warda, A., Lochner, D. and Birchmeier, W. (1991) E-cadherin-mediated cellcell adhesion prevents invasiveness of human carcinoma cells. $J$. Cell Biol. 113, 173-185.

Fujita, Y., Krause, G., Scheffner, M., Zechner, D., Leddy, H. E., Behrens, J., Sommer, T. and Birchmeier, W. (2002) Hakai, a c-Cbl-like protein, ubiquitinates and induces endocytosis of the E-cadherin complex. Nat. Cell Biol. 4, 222-231.

Fuxe, J., Vincent, T. and Garcia de Herreros, A. (2010) Transcriptional crosstalk between TGF-beta and stem cell pathways in tumor cell invasion: role of EMT promoting Smad complexes. Cell Cycle 9, 2363-2374.

Gravdal, K., Halvorsen, O. J., Haukaas, S. A. and Akslen, L. A. (2007) A switch from $\mathrm{E}$-cadherin to $\mathrm{N}$-cadherin expression indicates epithelial to mesenchymal transition and is of strong and independent importance for the progress of prostate cancer. Clin. Cancer Res. 13, 7003-7011.

Grille, S. J., Bellacosa, A., Upson, J., Klein-Szanto, A. J., van Roy, F., Lee-Kwon, W., Donowitz, M., Tsichlis, P. N. and Larue, L. (2003) The protein kinase Akt induces epithelial mesenchymal transition and promotes enhanced motility and invasiveness of squamous cell carcinoma lines. Cancer Res. 63, 2172-2178.

Guilford, P., Hopkins, J., Harraway, J., McLeod, M., McLeod, N., Harawira, P., Taite, H., Scoular, R., Miller, A. and Reeve, A. E. (1998) $\mathrm{E}$-cadherin germline mutations in familial gastric cancer. Nature 392, 402-405.

Hao, J., Zhang, Y., Deng, M., Ye, R., Zhao, S., Wang, Y., Li, J. and Zhao, Z. (2014) MicroRNA control of epithelial-mesenchymal transition in cancer stem cells. Int. J. Cancer 135, 1019-1027.

Hartwell, K. A., Muir, B., Reinhardt, F., Carpenter, A. E., Sgroi, D. C. and Weinberg, R. A. (2006) The Spemann organizer gene, Goosecoid, promotes tumor metastasis. Proc. Natl. Acad. Sci. U.S.A. 103, 18969-18974.

Hay, E. D. (2005) The mesenchymal cell, its role in the embryo, and the remarkable signaling mechanisms that create it. Dev. Dyn. 233, 706-720.

Hodge, D. R., Hurt, E. M. and Farrar, W. L. (2005) The role of IL-6 and STAT3 in inflammation and cancer. Eur. J. Cancer 41, 2502-2512.

Hugo, H., Ackland, M. L., Blick, T., Lawrence, M. G., Clements, J. A., Williams, E. D. and Thompson, E. W. (2007) Epithelial--mesenchymal and mesenchymal--epithelial transitions in carcinoma progression. J. Cell. Physiol. 213, 374-383.

Iwano, M., Fischer, A., Okada, H., Plieth, D., Xue, C., Danoff, T. M. and Neilson, E. G. (2001) Conditional abatement of tissue fibrosis using nucleoside analogs to selectively corrupt DNA replication in transgenic fibroblasts. Mol. Ther. 3, 149-159.

Iwano, M., Plieth, D., Danoff, T. M., Xue, C., Okada, H. and Neilson, E. G. (2002) Evidence that fibroblasts derive from epithelium during tissue fibrosis. J. Clin. Invest. 110, 341-350.

Kalluri, R. and Neilson, E. G. (2003) Epithelial-mesenchymal transition and its implications for fibrosis. J. Clin. Invest. 112, 1776-1784.

Karafiat, V., Dvorakova, M., Krejci, E., Kralova, J., Pajer, P., Snajdr, P., 
Mandikova, S., Bartunek, P., Grim, M. and Dvorak, M. (2005) Transcription factor c-Myb is involved in the regulation of the epithelialmesenchymal transition in the avian neural crest. Cell. Mol. Life Sci. 62, 2516-2525.

Karafiat, V., Dvorakova, M., Pajer, P., Cermak, V. and Dvorak, M. (2007) Melanocyte fate in neural crest is triggered by Myb proteins through activation of c-kit. Cell. Mol. Life Sci. 64, 2975-2984.

Kim, B. N., Ahn, D. H., Kang, N., Yeo, C. D., Kim, Y. K., Lee, K. Y., Kim, T. J., Lee, S. H., Park, M. S., Yim, H. W., Park, J. Y., Park, C. K. and Kim, S. J. (2020) TGF-beta induced EMT and stemness characteristics are associated with epigenetic regulation in lung cancer. Sci. Rep. 10, 10597.

Kim, C. F., Jackson, E. L., Woolfenden, A. E., Lawrence, S., Babar, I., Vogel, S., Crowley, D., Bronson, R. T. and Jacks, T. (2005) Identification of bronchioalveolar stem cells in normal lung and lung cancer. Cell 121, 823-835

Lamouille, S., Xu, J. and Derynck, R. (2014) Molecular mechanisms of epithelial-mesenchymal transition. Nat. Rev. Mol. Cell Biol. 15, 178-196.

Lander, R., Nordin, K. and LaBonne, C. (2011) The F-box protein Ppa is a common regulator of core EMT factors Twist, Snail, Slug, and Sip1. J. Cell Biol. 194, 17-25.

Lee, J. M., Dedhar, S., Kalluri, R. and Thompson, E. W. (2006a) The epithelial-mesenchymal transition: new insights in signaling, development, and disease. J. Cell Biol. 172, 973-981.

Lee, T. K., Poon, R. T., Yuen, A. P., Ling, M. T., Kwok, W. K., Wang, X. H., Wong, Y. C., Guan, X. Y., Man, K., Chau, K. L. and Fan, S. T. (2006b) Twist overexpression correlates with hepatocellular carcinoma metastasis through induction of epithelial-mesenchymal transition. Clin. Cancer Res. 12, 5369-5376.

Leptin, M. (1999) Gastrulation in Drosophila: the logic and the cellular mechanisms. EMBO J. 18, 3187-3192.

Leptin, M. and Affolter, M. (2004) Drosophila gastrulation: identification of a missing link. Curr. Biol. 14, R480- R482.

Li, Y., Yang, J., Dai, C., Wu, C. and Liu, Y. (2003) Role for integrinlinked kinase in mediating tubular epithelial to mesenchymal transition and renal interstitial fibrogenesis. J. Clin. Invest. 112, 503-516.

Lim, S., Becker, A., Zimmer, A., Lu, J., Buettner, R. and Kirfel, J. (2013) SNAl1-mediated epithelial-mesenchymal transition confers chemoresistance and cellular plasticity by regulating genes involved in cell death and stem cell maintenance. PLOS ONE 8, e66558.

Liu, Y., Lu, X., Huang, L., Wang, W., Jiang, G., Dean, K. C., Clem, B., Telang, S., Jenson, A. B., Cuatrecasas, M., Chesney, J., Darling, D. S., Postigo, A. and Dean, D. C. (2014) Different thresholds of ZEB1 are required for Ras-mediated tumour initiation and metastasis. Nat. Commun. 5, 5660 .

Maiuthed, A., Chantarawong, W. and Chanvorachote, P. (2018) Lung cancer stem cells and cancer stem cell-targeting natural compounds. Anticancer Res. 38, 3797-3809.

Mani, S. A., Yang, J., Brooks, M., Schwaninger, G., Zhou, A., Miura, N., Kutok, J. L., Hartwell, K., Richardson, A. L. and Weinberg, R. A. (2007) Mesenchyme Forkhead 1 (FOXC2) plays a key role in metastasis and is associated with aggressive basal-like breast cancers. Proc. Natl. Acad. Sci. U.S.A. 104, 10069-10074.

Monsoro-Burq, A. H., Wang, E. and Harland, R. (2005) Msx1 and Pax3 cooperate to mediate FGF8 and WNT signals during Xenopus neural crest induction. Dev. Cell 8, 167-178.

Nishitani, Y., Iwano, M., Yamaguchi, Y., Harada, K., Nakatani, K., Akai, Y., Nishino, T., Shiiki, H., Kanauchi, M., Saito, Y. and Neilson, E. G. (2005) Fibroblast-specific protein 1 is a specific prognostic marker for renal survival in patients with IgAN. Kidney Int. 68, 1078-1085.

Okada, H., Ban, S., Nagao, S., Takahashi, H., Suzuki, H. and Neilson, E. G. (2000) Progressive renal fibrosis in murine polycystic kidney disease: an immunohistochemical observation. Kidney Int. 58, 587-597.

Okada, H., Danoff, T. M., Kalluri, R. and Neilson, E. G. (1997) Early role of Fsp1 in epithelial-mesenchymal transformation. Am. J. Physiol. 273, F563- F574.

Okada, H., Strutz, F., Danoff, T. M., Kalluri, R. and Neilson, E. G. $(1996)$ Possible mechanisms of renal fibrosis. Contrib. Nephrol. 118, 147-154.

Oloumi, A., McPhee, T. and Dedhar, S. (2004) Regulation of E-cad- herin expression and beta-catenin/Tcf transcriptional activity by the integrin-linked kinase. Biochim. Biophys. Acta 1691, 1-15.

Otsuki, Y., Saya, H. and Arima, Y. (2018) Prospects for new lung cancer treatments that target EMT signaling. Dev. Dyn. 247, 462-472.

Pan, J., Fang, S., Tian, H., Zhou, C., Zhao, X., Tian, H., He, J., Shen, W., Meng, X., Jin, X. and Gong, Z. (2020) IncRNA JPX/miR-33a-5p/ Twist 1 axis regulates tumorigenesis and metastasis of lung cancer by activating Wnt/beta-catenin signaling. Mol. Cancer 19, 9 .

Pece, S. and Gutkind, J. S. (2002) E-cadherin and Hakai: signalling, remodeling or destruction? Nat. Cell Biol. 4, E72- E74.

Peinado, H., Olmeda, D. and Cano, A. (2007) Snail, Zeb and bHLH factors in tumour progression: an alliance against the epithelial phenotype? Nat. Rev. Cancer 7, 415-428.

Perl, A. K., Wilgenbus, P., Dahl, U., Semb, H. and Christofori, G. (1998) A causal role for E-cadherin in the transition from adenoma to carcinoma. Nature 392, 190-193.

Pires, B. R., Mencalha, A. L., Ferreira, G. M., de Souza, W. F., Morgado-Diaz, J. A., Maia, A. M., Correa, S. and Abdelhay, E. S. (2017) NF-kappaB is involved in the regulation of EMT genes in breast cancer cells. PLoS ONE 12, e0169622.

Polakis, P. (2000) Wnt signaling and cancer. Genes Dev. 14, 18371851

Prudkin, L., Liu, D. D., Ozburn, N. C., Sun, M., Behrens, C., Tang, X., Brown, K. C., Bekele, B. N., Moran, C. and Wistuba, I. I. (2009) Epithelial-to-mesenchymal transition in the development and progression of adenocarcinoma and squamous cell carcinoma of the lung. Mod. Pathol. 22, 668-678.

Sato, R., Semba, T., Saya, H. and Arima, Y. (2016) Concise review: stem cells and epithelial-mesenchymal transition in cancer: biological implications and therapeutic targets. Stem Cells 34, 1997-2007.

Sauka-Spengler, T. and Bronner-Fraser, M. (2008) A gene regulatory network orchestrates neural crest formation. Nat. Rev. Mol. Cell Biol. 9, 557-568.

Seo, J., Ha, J., Kang, E. and Cho, S. (2021) The role of epithelial-mesenchymal transition-regulating transcription factors in anti-cancer drug resistance. Arch. Pharm. Res. 44, 281-292.

Shaw, A. T. and Solomon, B. (2011) Targeting anaplastic lymphoma kinase in lung cancer. Clin. Cancer Res. 17, 2081-2086.

Shih, J. Y., Tsai, M. F., Chang, T. H., Chang, Y. L., Yuan, A., Yu, C. J., Lin, S. B., Liou, G. Y., Lee, M. L., Chen, J. J., Hong, T. M., Yang, S. C., Su, J. L., Lee, Y. C. and Yang, P. C. (2005) Transcription repressor slug promotes carcinoma invasion and predicts outcome of patients with lung adenocarcinoma. Clin. Cancer Res. 11, 80708078.

Shin, S. Y., Rath, O., Zebisch, A., Choo, S. M., Kolch, W. and Cho, K. H. (2010) Functional roles of multiple feedback loops in extracellular signal-regulated kinase and Wnt signaling pathways that regulate epithelial-mesenchymal transition. Cancer Res. 70, 67156724.

Strutz, F., Okada, H., Lo, C. W., Danoff, T., Carone, R. L., Tomaszewski, J. E. and Neilson, E. G. (1995) Identification and characterization of a fibroblast marker: FSP1. J. Cell Biol. 130, 393-405.

Strutz, F., Zeisberg, M., Ziyadeh, F. N., Yang, C. Q., Kalluri, R., Muller, G. A. and Neilson, E. G. (2002) Role of basic fibroblast growth factor-2 in epithelial-mesenchymal transformation. Kidney Int. 61, 1714-1728.

Sung, H., Ferlay, J., Siegel, R. L., Laversanne, M., Soerjomataram, I., Jemal, A. and Bray, F. (2021) Global cancer statistics 2020: GLOBOCAN estimates of incidence and mortality worldwide for 36 cancers in 185 countries. CA Cancer J. Clin. 71, 209-249.

Tepass, U. (1996) Crumbs, a component of the apical membrane, is required for zonula adherens formation in primary epithelia of Drosophila. Dev. Biol. 177, 217-225.

Tepass, U., Theres, C. and Knust, E. (1990) crumbs encodes an EGFlike protein expressed on apical membranes of Drosophila epithelial cells and required for organization of epithelia. Cell 61, 787-799.

Teschendorff, A. E., Journee, M., Absil, P. A., Sepulchre, R. and Caldas, C. (2007) Elucidating the altered transcriptional programs in breast cancer using independent component analysis. PLOS Comput. Biol. 3, e161.

Thiery, J. P., Acloque, H., Huang, R. Y. and Nieto, M. A. (2009) Epithelial-mesenchymal transitions in development and disease. Cell 
139, 871-890.

Thiery, J. P. and Sleeman, J. P. (2006) Complex networks orchestrate epithelial-mesenchymal transitions. Nat. Rev. Mol. Cell Biol. 7, 131-142.

Timmerman, L. A., Grego-Bessa, J., Raya, A., Bertran, E., PerezPomares, J. M., Diez, J., Aranda, S., Palomo, S., McCormick, F., Izpisua-Belmonte, J. C. and de la Pompa, J. L. (2004) Notch promotes epithelial-mesenchymal transition during cardiac development and oncogenic transformation. Genes Dev. 18, 99-115.

Tucker, G. C., Duband, J. L., Dufour, S. and Thiery, J. P. (1988) Celladhesion and substrate-adhesion molecules: their instructive roles in neural crest cell migration. Development 103 Suppl, 81-94.

Ungefroren, H., Witte, D. and Lehnert, H. (2018) The role of small GTPases of the Rho/Rac family in TGF-beta-induced EMT and cell motility in cancer. Dev. Dyn. 247, 451-461.

Valcourt, U., Kowanetz, M., Niimi, H., Heldin, C. H. and Moustakas, A. (2005) TGF-beta and the Smad signaling pathway support transcriptomic reprogramming during epithelial-mesenchymal cell transition. Mol. Biol. Cell 16, 1987-2002.

Wang, D., Dai, C., Li, Y. and Liu, Y. (2011) Canonical Wnt/beta-catenin signaling mediates transforming growth factor-beta1-driven podocyte injury and proteinuria. Kidney Int. 80, 1159-1169.

Wang, G., Guo, X., Hong, W., Liu, Q., Wei, T., Lu, C., Gao, L., Ye, D., Zhou, Y., Chen, J., Wang, J., Wu, M., Liu, H. and Kang, J. (2013) Critical regulation of miR-200/ZEB2 pathway in Oct4/Sox2-induced mesenchymal-to-epithelial transition and induced pluripotent stem cell generation. Proc. Natl. Acad. Sci. U.S.A. 110, 2858-2863.

Wang, J., Sridurongrit, S., Dudas, M., Thomas, P., Nagy, A., Schneider, M. D., Epstein, J. A. and Kaartinen, V. (2005) Atrioventricular cushion transformation is mediated by ALK2 in the developing mouse heart. Dev. Biol. 286, 299-310.

Wellner, U., Schubert, J., Burk, U. C., Schmalhofer, O., Zhu, F., Sonntag, A., Waldvogel, B., Vannier, C., Darling, D., zur Hausen, A., Brunton, V. G., Morton, J., Sansom, O., Schuler, J., Stemmler, M. P., Herzberger, C., Hopt, U., Keck, T., Brabletz, S. and Brabletz, T. (2009) The EMT-activator ZEB1 promotes tumorigenicity by re- pressing stemness-inhibiting microRNAs. Nat. Cell Biol. 11, 14871495.

Weston, J. A. (1970) The migration and differentiation of neural crest cells. Adv. Morphog. 8, 41-114.

Wu, D. and Wang, X. (2015) Application of clinical bioinformatics in lung cancer-specific biomarkers. Cancer Metastasis Rev. 34, 209216.

Xie, L., Law, B. K., Chytil, A. M., Brown, K. A., Aakre, M. E. and Moses, H. L. (2004) Activation of the Erk pathway is required for TGFbeta1-induced EMT in vitro. Neoplasia 6, 603-610.

Yang, J., Mani, S. A., Donaher, J. L., Ramaswamy, S., Itzykson, R. A., Come, C., Savagner, P., Gitelman, I., Richardson, A. and Weinberg, R. A. (2004) Twist, a master regulator of morphogenesis, plays an essential role in tumor metastasis. Cell 117, 927-939.

Yang, Z., Rayala, S., Nguyen, D., Vadlamudi, R. K., Chen, S. and Kumar, R. (2005) Pak1 phosphorylation of snail, a master regulator of epithelial-to-mesenchyme transition, modulates snail's subcellular localization and functions. Cancer Res. 65, 3179-3184.

Zeisberg, M., Bonner, G., Maeshima, Y., Colorado, P., Muller, G. A., Strutz, F. and Kalluri, R. (2001) Renal fibrosis: collagen composition and assembly regulates epithelial-mesenchymal transdifferentiation. Am. J. Pathol. 159, 1313-1321.

Zhang, P., Sun, Y. and Ma, L. (2015) ZEB1: at the crossroads of epithelial-mesenchymal transition, metastasis and therapy resistance. Cell Cycle 14, 481-487.

Zhang, Y. and Weinberg, R. A. (2018) Epithelial-to-mesenchymal transition in cancer: complexity and opportunities. Front. Med. 12, 361373.

Zhou, B. P., Deng, J., Xia, W., Xu, J., Li, Y. M., Gunduz, M. and Hung, M. C. (2004) Dual regulation of Snail by GSK-3beta-mediated phosphorylation in control of epithelial-mesenchymal transition. Nat. Cell Biol. 6, 931-940.

Zhou, J. J., Meng, Z., Zhou, Y., Cheng, D., Ye, H. L., Zhou, Q. B. Deng, X. G. and Chen, R. F. (2016) Hepatitis C virus core protein regulates OCT4 expression and promotes cell cycle progression in hepatocellular carcinoma. Oncol. Rep. 36, 582-588. 